\title{
THE ROLE OF THE PSYCHOLOGIST IN THE TREATMENT OF SPINAL CORD INJURY ${ }^{1}$
}

\author{
Roberta B. Trieschmann, Ph.D. \\ Spinal Cord Injury Project Director, Easter Seal Society of Los Angeles County, \\ Los Angeles, California, U.S.A.
}

\begin{abstract}
Advances in the treatment of spinal cord injury have shifted the emphasis from problems of survival to problems of psychological integration into the community. However, the patient's expectations for a fairly normal life are often not realised because of discrimination against disabled persons by able-bodied persons. Therefore, rehabilitation should include psychosocial skills training to teach spinal cord injury persons to cope with these issues in their own world. To accomplish this, the psychologist can contribute to the rehabilitation process as a consultant to the rehabilitation team, as a researcher of the rehabilitation process, as an evaluator of patient skills and strengths, and as a counsellor. Each of these roles is discussed and a conceptualisation of the rehabilitation process is presented.
\end{abstract}

Key words: Spinal cord injury; Psychologists; Rehabilitation; Behaviour therapy.

DURING a conference on research issues in spinal cord injury, Dr George Hohmann, chief psychologist at the Veterans Administration Hospital in Tucson, Arizona, himself a paraplegic, stated, 'Patients today may not be as depressed as patients were 20 or 30 years ago. But when I was injured 32 years ago, I was jolly well depressed, as I look back on it, because I was told that I would be dead in 2 years. I was told that I would never marry. I was told that I would never have a family. I was told that I would be in an institution for the remainder of my life. The expectancies were set by the institution and by the then-prevailing knowledge. Today, patients are given, even in the very worst of centres, a very different type of expectation' (Research Issues in the Psychological, Social, and Vocational Adjustment to Spinal Cord Injury: Professional Conference, 1977).

Treatment of spinal cord injury has advanced tremendously since I944, thanks to the efforts of Sir Ludwig Guttmann (1967) and others, and today anyone who survives the initial trauma of spinal cord injury has a good chance of living a long and potentially satisfying life. Bladder, kidney, respiratory, and skin problems can be managed and complications prevented if the individual carries out the procedures and techniques that he is taught in the rehabilitation centre.

Thus, the information which we give to the newly injured person sets the expectation that he will have a fairly normal life. We advise him that he will learn to get around in a wheelchair, and to take care of himself (if he is a paraplegic), and that education and vocational retraining are possibilities for the future. He is told that he will be able to return home and a family life is a possibility also.

However, data are being collected which suggested that many spinal cord injury persons are not very satisfied with their lives. For example, Wilcox and

1 This work has been supported in part by Grant number I3-P-590II/9-0I of the Rehabilitation Services Administration of the United States Department of Health, Education, and Welfare. 
Stauffer (1972) followed 423 spinal cord injury patients at Rancho Los Amigos Hospital and found that 44 per cent $(N=50)$ were known to be dead. Thirty-four per cent of the deaths $(N=17)$ resulted from avoidable conditions such as overdose of drugs and/or alcohol, suicide, and multiple pressure sores with sepsis. Ninetyfour per cent $(N=\mathrm{I} 6)$ of these avoidable deaths occurred before the sixth anniversary of their injury. Fifty-three per cent $(N=9)$ of these avoidable deaths were known suicides.

Price (1973) followed 227 patients at the University of Minnesota and found that 48 per cent $(N=5)$ of the I I deaths occurred in individuals who exhibited severe personality problems which contributed to the patients' demise. Price states, 'The primary concern for patients with spinal cord injury has traditionally been focused upon physical and vocational rehabilitation. The importance of these facets of rehabilitation is undeniable. However, the influence of emotional disability upon the cause of death in six of eleven patients, emphasises the need for the better use of available methods of prediction and the development of new tools for coping with the emotional needs of the severely handicapped'.

In a study of United States veterans, Nyquist and Bors (1967) found that suicide occurred in 8.1 per cent of the 258 deaths in traumatic injury cases. At Edenhall Hospital in Scotland, Kerr and Thompson (1972) found that eight out of eleven older individuals rated as having failed in their mental adjustment to spinal cord injury were dead at the time of follow-up. However, they believe that attention should not be given only to problem cases, but each person may have some difficulty in coping with the stress of spinal cord injury. They caution that, 'It is a grave mistake to think that an articulate educated man does not need skilled help with adjustment problems ... (or) to feel all is well because the patient is talking intelligently about his condition and making practical plans'. And Hallin (1968) in a follow-up study at the Kenny Rehabilitation Institute concludes, 'That psychological adjustment, rather than intellectual capacity or the level or completeness of injury, is the critical factor in determining rehabilitation success'.

In addition to the statistics on avoidable death, further data suggest that there may be a discrepancy between the spinal injury patients' expectations for a fairly normal life and their actual accomplishments. Cogswell (I968) found that most individuals with spinal cord injury tend to withdraw from social contacts following discharge from the rehabilitation centre and tend to stay in the home. Only six of the 26 in her sample were working at the time of follow-up. Some individuals get involved in educational programmes or vocational retraining, but only a small percentage oî spinal cord injury persons in the United States obtain and retain a financially independent status (Comprehensive Service Needs Study, 1976). While data on United States veterans suggest that pre-injury and postinjury marriages fail at approximately the same rate of 23-26 per cent, as noted by El Ghatit and Hanson (1975, 1976), there is concern that these data are not representative of the civilian spinal cord injury population and that civilian pre-injury marriages, without the financial security of a veteran's pension, may fail at an alarming rate (Research Issues in the Psychological, Social, and Vocational Adjustment in Spinal Cord Injury: Consumer Conference, 1977).

Thus, the data suggest that although most spinal cord injury persons are living much longer than they did in 1944, many of them are having trouble in coping with the world outside of the hospital. This world is designed for and occupied by able-bodied people who are not very accepting of those with disabilities. In fact, many disabled people have stated that the attitudes of society are more handicapping than their mobility impairment. Yet, during the inpatient 
rehabilitation phase, a very small proportion of the treatment programme, if any, is devoted to social and psychological rehabilitation.

Therefore, it is time to state that we can offer individuals with spinal cord injury something better than almost certain social and psychological stagnation. We do have techniques available to teach persons with spinal cord injury to cope with the devaluation that they experience in the able-bodied world. And we do have psychologists, social workers, and recreational therapists who are convinced that their services can make a critical difference in the ultimate functioning of the spinal cord injured person.

It is important to note that the onset of spinal cord injury does not lead to psychological problems of the kind that one associates with psychiatric diagnoses. Rather, spinal cord injury produces problems in living, which are reality problems associated with the fact that major changes must be made in how one relates to the world. Hohmann (1975) states that 'these reactions are normal sequelae to any severe loss and might be described as normal reactions to an abnormal situation'.

If we accept the assumption that only a small proportion of persons with spinal cord injury display sufficiently disruptive behaviour to warrant a psychiatric diagnosis (Munro, I954), and if we also believe that most of the psychological reactions to spinal cord injury are normal reactions to stress, then why should spinal cord injury centres utilise the services of clinical psychologists? The answer to this question depends on one's definition of rehabilitation. Does rehabilitation consist of learning self-care and mobility techniques alone or does rehabilitation consist of teaching a person to apply these techniques to the problems of living?

I belive that rehabilitation is the process of teaching a person to cope with his disability outside of the hospital and, thereby, providing him with the opportunity to achieve a fairly normal and satisfying life. A satisfying life is influenced by many factors, one's personality, one's environment, and one's biological system. Since the ultimate focus of all rehabilitation efforts is the behaviour of the disabled person, the following conceptual framework elucidates some of the factors which influence what the person actually does do in any given situation. Behaviour is a function of the person, the organism, and the environment: $\mathrm{B}=f(\mathrm{P} \times \mathrm{O} \times \mathrm{E})$ (see Fig. I.) Most of the treatment time in a rehabilitation centre focuses on behaviours related to organic factors $(\mathrm{O})$, such as skin care, bladder and bowel care, and techniques of mobilisation and self-care which circumvent the paralysis. But little treatment time is devoted to teaching the person (P) to cope with his own world (E) in search of satisfaction and productivity. It is to participate in this task that the clinical psychologist can play a very important role.

Therefore, I would like to propose that the clinical psychologist can contribute to the rehabilitation process in four ways: ( $\mathrm{I}$ ) Consultation with the rehabilitation team: (a) application of principles of learning to the rehabilitation process in general, and $(b)$ specific applications of the principles of learning to individual cases; (2) Research into the rehabilitation process; (3) Psychological evaluation of patient assets and strengths; and (4) Counselling and therapy.

Based on the premise that rehabilitation is the process of learning to live with one's disability in one's own environment, the psychologist's training in the principles of behaviour, and in particular, in the principles of learning allows him or her to make a unique contribution to the rehabilitation process. For example, the person with a spinal cord injury faces a formidable task as he copes with an environment which he had previously taken for granted. He must learn to feed, bathe, and dress himself, learn to transfer and use a wheelchair, learn to face people 
$\mathbf{P}=$ Person variables

Repertoire of habits

Personality style

Types of rewards

Internal $v$. external locus of control

Method of coping with stress

Self-image
$\mathbf{O}=$ Organismic variables

Age

Level of injury and functional limitations

Medical complications

Congenital anomalies

Strength

Endurance

\section{$\mathbf{E}=$ Environmental variables}

Hospital milieu

Stigma value of disability

Family support

Financial security

Social milieu

Urban $v$. rural residence

Access to medical attention and equipment repair

Access to educational, recreational, and vocational pursuits

$\mathrm{B}=f(\mathrm{P} \times \mathrm{O} \times \mathrm{E})$. Behaviour is a function of the Person $(\mathrm{P})$, the Organism $(\mathrm{O})$, and the Environment (E).

FIG. I

who now convey that he is different from whom he used to be and, perhaps 'less' than he used to be. He must learn new types of recreation and leisure-time activities, and, perhaps, a new vocation. Following an educational or vocational training programme, he must learn to face potential employers who do not want to hire him, not because he is not qualified but because he is disabled. He must learn that many of his previous friends drift away from him and he must seek opportunities to meet new people and make new friends. Yet strangers tend to avoid any interaction with him; thus, he must learn techniques to put others at ease and he must teach them to forget that he is in the wheelchair. Rehabilitation is a learning process, and each member of the team becomes a teacher. Consequently, the principles of learning become very important to effective rehabilitation.

Traditionally, we have categorised our patients into two groups, those that are motivated and those that are unmotivated. And we all bemoan the difficulties of dealing with the unmotivated person. Yet which definition of motivation one uses determines the probability of success with the unmotivated person. Some define motivation as an internal drive state that propels the person in the 'proper' direction. However, if the person lacks motivation, it is difficult to influence this inner state, and psychotherapy has not been very successful as a remedy (Margolin, 197I). But if motivation is defined as those rewards, satisfactions, and pay-offs in the environment for which the person will work, the problem is external to the individual and capable of being influenced by the treatment team. Thus, if we conceptualise motivation as an inner drive state, then it is the patient's fault that he does not adjust to his disability. However, if we use the reinforcer or external concept of motivation, then it may be our fault if the person does not adjust to his disability (Trieschmann, 1974). Use of the reinforcer concept of motivation places more responsibility on the rehabilitation team for patient failures, but it also provides us with a strategy to reduce the number of failures and assist each individual in achieving some measure of satisfaction in his life.

This strategy which is available to the rehabilitation team consists of providing environmental rewards for the new behaviours which the spinal injury person must learn. And, therefore, our emphasis must shift from inside of the person to outside of him, to the environment in which the behaviour will occur. Willems (1976)

$$
\text { I6/2-P }
$$


indicates that the central problems of rehabilitation involve performance and environment and we can influence performance significantly by varying the environment in which it occurs.

Therefore, the psychologist within the spinal cord injury centre should consult with the rehabilitation team as to the method by which we can produce the most efficient learning of rehabilitation procedures and new behaviours. This consultation relates to the application of the principles of learning to the entire rehabilitation process in general and to individual cases. The focus of these consultations will be on how we can arrange the hospital environment to reward the desired behaviours on the part of the patient. Entailed in this concept is the recognition that each team member forms part of the patient's environment and, thus, is a rewarder or punisher of the patient's behaviour during every behavioural interaction. Consequently, each of us must be willing to look at our own behaviour in terms of its effect on the patient.

In addition, application of this approach to motivation must occur within the rehabilitation process itself, not removed from it to the psychologist's office. That is, if a patient is performing poorly in physical therapy, the focus of the treatment is the interaction between patient and physical therapist, and not a counselling session in the psychologist's office.

Because the rehabilitation environment is very influential in determining the outcome in each case, it is important to define the multiple parameters of the rehabilitation process and determine their individual and combined effects on the behaviour of the spinal cord injury patient. Therefore, an additional and important role for the clinical psychologist in the spinal cord injury centre is as a researcher. The psychologist's training includes an extensive background in research techniques which can be utilised to study the rehabilitation process. This combination of clinical and research training is unique within the rehabilitation team and ideal for the study of means by which we can increase the effectiveness of our rehabilitation efforts. Studies at the Texas Institute of Rehabilitation and Research by Willems (1976) and his colleagues have demonstrated the importance of studying the interaction between the spinal cord injury patient and the hospital environment in order to measure outcomes of our rehabilitation efforts and to monitor the effects of our treatment techniques. This data can help us update our methods and improve the efficiency of our rehabilitation procedures. Therefore, the participation of a clinical psychologist on the treatment team and on the research team provides a liaison between theory and reality.

A third role for the psychologist is to provide an assessment of individual spinal cord injury patients so that the information can be used by the patient to set realistic goals for his future. Such an assessment would utilise some psychological tests, interviews, and observations of the patient in action in order to estimate the person's strength and skills. This information can help the team plan an individualised treatment programme utilising rewards that will be meaningful to the individual patient in achieving his goals. I have placed this role of the psychologist third in order of priority because psychological testing that occurs without the behavioural consultation role described above can often be meaningless. In addition, to perceive the psychologist as primarily a psychodiagnostician of patients is to perceive the patient as being the locus of the motivational problem rather than the environment. And unfortunately, in these situations, psychological tests may work against the patient rather than for him as they were originally designed to do.

And there is a fourth role for the psychologist, as a therapist and counsellor. 
Since other members of the treatment team may be trained in counselling also, this role is not unique to the psychologist. But there are never enough counsellors for all the patients in any centre. A small percentage of spinal cord injury persons may have pre-injury personality problems which will be aggravated by the disability, and counselling may be helpful. The remainder of the population who are experiencing 'normal reactions to abnormal situations' may welcome the opportunity to talk with someone about the future and the impact of the disability upon his life. This opportunity should be made available to each spinal cord injury person. However, in the author's experience, many spinal injury persons do not perceive the need for a psychotherapist per se and often prefer to focus on the more physical aspects of treatment, especially during the initial phases of rehabilitation. Also, they often benefit from the opportunity to talk with an experienced disabled person in order to share knowledge relevant to coping with the world outside of the hospital.

Consequently, I have placed the role of counsellor fourth in order of priority because I do not believe that persons with spinal cord injury have psychological problems per se. Rather they have problems in learning to cope with an environment which requires new ways of behaving. As a result, I have emphasised the role of behavioural consultant to the rehabilitation team as that role which will make a unique contribution to our most important goal, assisting the person with spinal injury to achieve the highest level of functioning possible in a world with some opportunity of reward for him.

To achieve some measure of reward upon discharge from the rehabilitation centre, the person needs a repertoire of social skills which will help him battle the devaluation he will experience from others, help him to reduce the social anxiety which his presence will generate in a group of strangers, and help him to overcome the scepticism which an employer may have about his suitability for a job. Thus, in the role of behavioural consultant, the psychologist can help to implement a number of psychological techniques which will enhance these social skills, such as role playing, modelling, peer counselling, and assertion training, all of which should be a routine part of any rehabilitation programme. With this step, we can advance the state-of-the-art of the rehabilitation process as emphasis shifts from problems of survival to ones of psychosocial integration into the community.

\section{Conclusions}

It is a thesis of this paper that persons with spinal cord injury do not have psychological problems per se as a result of the injury but rather have problems in coping with a world designed for non-disabled people. Thus, we believe that rehabilitation is the process of teaching the person to cope with his own world following spinal injury. The clinical psychologist can play a significant role in the treatment of spinal injury as a behavioural consultant to the rehabilitation team, as a researcher into the rehabilitation process, as an evaluator of the psychological strengths and assets of the person with spinal injury, and as a therapist and counsellor.

The traditional emphasis on the psychologist's role as a psychodiagnostician and counsellor only is not consistent with the view of rehabilitation presented here. Rather, in addition to these roles, the psychologist's unique skills in the application of the principles of learning and in the techniques of research can assist the rehabilitation team accomplish our goal, i.e. helping the person with spinal injury find some satisfaction within his own community. 


\section{RÉSUMÉ}

La thèse de cette note est que les personnes ayant une lésion à la moelle épinière n'ont pas des problèmes strictement psychologiques résultant de cette lésion. Plutôt, ils ont des problèmes pour s'adapter à un monde conçu pour des gens n'ayant pa cette incapacité. Ainsi, nous pensons que la réhabilitation est le processus qui consiste à enseigner à l'individu à se réadapter à son propre milieu après une lésion à la moelle épinière. Le psychologue clinicien peut jouer un rôle important dans le traitement des lésions à la moelle épinière comme expert-conseil à l'équipe de réhabilitation, comme chercheur en réhabilitation, et comme conseiller et thérapeute en mesure d'évaluer les atouts psychologiques du patient.

L'emphase traditionelle mise sur le rôle du psychologue en tant que uniquement conseiller et diagnosticien ne concorde pas avec la conception de la réhabilitation présentée. ici. Plutôt, outre ces rôles, les capacités uniques du psychologue dans l'application des principes d'enseignement et dans les techniques de recherche peuvent aider l'équipe de réhabilitation à atteindre notre but: aider la personne souffrant d'une lésion à la moelle épinière à trouver quelque satisfaction dans son propre milieu.

\section{ZUSAMMENFASSUNG}

Die These dieser Arbeit ist, daß Menschen mit Rückenmarksverletzung keine psychologischen Probleme per se als Folge der Verletzung haben, sondern vielmehr Schwierigkeiten, sich in einer für Unverletzte geschaffenen Welt zurechtzufinden. Daher ist nach unserer Meinung Rehabilitation der Prozeß, den Menschen zu lehren, nach der Rückenmarksverletzung mit seiner eigenen Welt fertig zu werden. In der Behandlung von Rückenmarksverletzungen kann der klinische Psychologe eine wichtige Rolle spielen als Verhaltensberater für das Rehabilitationsteam, Erforscher des Rehabilitationsprozesses, Erkenner der psychologischen Kräfte und Möglichkeiten des Verletzten, und als Therapeut und Ratgeber.

Die traditionelle Betonung der Rolle des Psychologen als Psychodiagnostiker und Ratgeber allein steht nicht im Einklang mit der hier dargestellten Auffassung der Rehabilitation. Über diese Aufgaben hinaus können vielmehr die besonderen Fähigkeiten des Psychologen das Rehabilitationsteam in der Erreichung unseres Ziels unterstützen: dem Rückenmarksverletzten zu helfen, etwas Befriedigung in seiner eigenen Umwelt zu finden.

\section{REFERENCES}

Cogswell, B. E. (1965). Self socialization: readjustment of paraplegics in the community. Fournal of Rehabilitation, 34, I I-I3.

Comprehensive SeRvice NeEdS Study. (1975). Urban Institute, Washington, D.C.

El Ghatit, A. Z. \& Hanson, R. W. (I975). Outcome of marriages existing at the time of a male's spinal cord injury. Fournal of Chronic Diseases, 21, 383-388.

El Ghatit, A. Z. \& HANson, R. W. (1976). Marriage and divorce after spinal cord injury. Archives of Physical Medicine and Rehabilitation, 57, 470-472.

GutTMANN, L. (1967). History of the national spinal injuries centre, Stoke Mandeville Hospital, Aylesbury. Paraplegia, 5, I I5-I26.

Hallin, R. P. (I968). Follow-up of paraplegics and tetraplegics after comprehensive rehabilitation. Paraplegia, 6, I28-1 34.

HohmanN, G. W. (I975). Psychological aspects of treatment and rehabilitation of the spinal injured person. Clinical Orthopedics, 112, 8I-88.

KeRR, W. G. \& THOMPSON, M. A. (I972). Acceptance of disability of sudden onset in paraplegia. Paraplegia, II, 94-102.

MARGolin, R. J. (I97I). Motivational problems and resolutions in the rehabilitation of paraplegics and quadriplegics. American Archives of Rehabilitation Therapy, 2I, 94-IO3.

MunRo, D. (1954). The rehabilitation of patients totally paralyzed below the waist, with special reference to making them ambulatory and capable of earning their own living: V. an end result study of 445 cases. New England fournal of Medicine, 252, 4-I4.

NyQuist, R. H. \& BORS, E. (1967). Mortality and survival in traumatic myelopathy during I9 years from 1946-1965. Paraplegia, 5, 22-48.

PRICE, M. (I973). Causes of death in I I of 227 patients with traumatic spinal cord injury over a period of nine years. Paraplegia, 11, 217-220. 
Research Issues in the Psychological, Social, and Vocational Adjustment to Spinal CORD INJURY: Consumer CONFERENCE (1977). Easter Seal Society of Los Angeles County, Los Angeles, California, June I I, 1977.

Research Issues in the Psychological, Social aNd Vocational Adjustment to Spinal CoRD InJURY: PROFESSIONALS ConfERENCE (1977). Easter Seal Society of Los Angeles County, Los Angeles, California, April 28-29, 1977.

TrieschmanN, R. B. (I974). Coping with a disability: a sliding scale of goals. Archives of Physical Medicine and Rehabilitation, 55, 556-560.

Wilcox, N. E. \& Stauffer, E. S. (1972). Follow-up of 423 consecutive patients admitted to the spinal cord centre, Rancho Los Amigos Hospital, I January to 3I December, 1967. Paraplegia, 10, I I5-I22.

Willems, E. P. (I976). Behavioral ecology, health status, and health care: applications to the rehabilitation setting. In I. Altman and J. F. Wohlwill (eds.), Human Behavior and Environment, pp. 2 I I-263. Plenum Publishing Corporation, New York. 